University of Nebraska - Lincoln

DigitalCommons@University of Nebraska - Lincoln

French Language and Literature Papers

Modern Languages and Literatures, Department

2021

Ouvrages de Lydie Salvayre

Warren Motte

Follow this and additional works at: https://digitalcommons.unl.edu/modlangfrench

Part of the French and Francophone Language and Literature Commons

This Article is brought to you for free and open access by the Modern Languages and Literatures, Department of at DigitalCommons@University of Nebraska - Lincoln. It has been accepted for inclusion in French Language and Literature Papers by an authorized administrator of DigitalCommons@University of Nebraska - Lincoln. 


\section{Ouvrages de Lydie Salvayre}

La Déclaration. Paris: Julliard, 1990. Paris: Verticales, 1997.

La Vie commune. Paris: Julliard, 1991. Paris: Verticales, 1999.

La Médaille. Paris: Seuil, 1993.

La Puissance des mouches. Paris: Seuil, 1995.

La Compagnie des spectres. Paris: Seuil, 1997.

Quelques Conseils utiles aux élèves huissiers. Paris: Verticales, 1997.

La Conférence de Cintegabelle. Paris: Seuil/Verticales, 1999.

Les Belles Âmes. Paris: Seuil, 2000.

Le Vif du vivant. Paris: Éditions Cercle d'Art, 2001.

Contre. Paris: Seuil/Verticales, 2002.

Et que les vers mangent le bœuf mort. Paris: Seuil/Verticales, 2002.

Passage à l'ennemie. Paris: Seuil, 2003.

La Méthode Mila. Paris Seuil, 2005.

Dis pas ça. Paris: Seuil/Verticales, 2006.

Published in Lydie Salvayre, maintenant même, ed. Warren Motte (Lincoln, NE : Zea Books, 2021). doi: 10.32873/unl.dc.zea.1291 
OUVRAGES DE LYDIE SALVAYRE

Portrait de l'écrivain en animal domestique. Paris: Seuil, 2007.

Petit Traité de l'éducation lubrique. Portiragnes: Cadex, 2008.

BW. Paris: Seuil, 2009.

Hymne. Paris: Seuil, 2011.

7 Femmes. Paris: Perrin, 2013.

Pas pleurer. Paris: Seuil, 2014.

Tout Homme est une nuit. Paris: Seuil, 2017.

Marcher jusqu'au soir. Paris: Stock, 2019. 